\title{
Food Additives in mozzarella Cheese: A Contribution for a Correct Analytical Determination
}

\author{
Aurelia Di Taranto, Mariateresa Ingegno, Anna Rita Ientile, Marco Iammarino \\ Struttura Complessa "Chimica" - Istituto Zooprofilattico Sperimentale della Puglia e della Basilicata, Via Manfredonia 20, Foggia, Italy
}

Email address:

marco.iammarino@tin.it (M. Iammarino)

\section{To cite this article:}

Aurelia Di Taranto, Mariateresa Ingegno, Anna Rita Ientile, Marco Iammarino. Food Additives in mozzarella Cheese: A Contribution for a Correct Analytical Determination. Journal of Food and Nutrition Sciences. Special Issue: Emerging Issues in Food Safety, Food Additives: Risk Assessment, Analytical Methods and Replacement in Foodstuffs. Vol. 3, No. 1-1, 2015, pp. 13-17. doi: 10.11648/j.jfns.s.2015030101.13

\begin{abstract}
Mozzarella is an unripened cheese widely consumed worldwide. Due to short shelf-life of these products, the addition of few food additives, such as citric acid and lactic acid is allowed by the actual Legislation. However, these two compounds are present in the aqueous phase of milk, making difficult a correct discrimination between products with added food additives from those declared as "with no added food additives". This work is collocated in this contest. It may be considered as a contribution for a correct food additives determination in mozzarella cheese. 14 samples ( 7 with citric acid declared on the label and 7 without declared food additives) were analysed, by using a reliable analytical method by ion chromatography with conductivity detection, for the quantification citric acid. The results were compared in order to verify a statistically significant difference between two data populations. The same samples were analysed, by using a validated ion chromatography with conductivity detection method, for the determination of lactic acid, and the results were evaluated in order to give a contribution to the determination of a maximum natural level of lactic acid in mozzarella cheese, in products without added food additives. Regarding citric acid, a cut-off value, equal to $0.65 \mathrm{~g} \mathrm{~kg}^{-1}$ was suggested as maximum admissible level in products without added food additives; while, as it concerns lactic acid, a maximum level corresponding to $4.0 \mathrm{~g} \mathrm{~kg}^{-1} \mathrm{was}_{\text {suggested. }}$
\end{abstract}

Keywords: Mozzarella, Citric Acid, Lactic Acid, Food Additives, Ion Chromatography, Conductivity Detection, Acidity Regulator

\section{Introduction}

Mozzarella is an unripened cheese widely consumed worldwide. As defined in Codex Standard for Mozzarella (CODEX STAN 262-2006), and in conformity with General Standard for Cheese (CODEX STAN 283-1978) and Codex Standard for Unripened Cheese Including Fresh Cheese (CODEX STAN 221-2001), it is a cheese characterised by a smooth elastic fibrous protein structure without defects. Mozzarella is produced by "pasta filata" processing, which consists in a curd heating at an appropriate $\mathrm{pH}$ and a consequent stretching. Mozzarella is a soft cheese, characterised by a near white colour, which may be packed with or without the liquid [1]. Due to short shelf-life of these products, the addition of food preservatives is not allowed by the actual Legislation. However, some other food additives, with different function, such as citric acid, lactic acid (Figure 1), acetic acid and glucono-delta-lattone, are admitted by the actual European Legislation, with no established maximum admissible levels (the Regulation reports the indication "quantum satis") [2]. Among others, citric acid is the most used in mozzarella as acidity regulator; however, it is an organic acid present in the aqueous phase of milk, where it influences coagulation, aromatic flavour and fermentation of dairy products, by interacting with other milk constituents [3-7]. A recent study [8] has underlined that the citric acid levels seem higher in mozzarella cheese and in cheese spread, in comparison to semi-hard and hard cheese samples. This difference was justified considering citric acid metabolism, carried out by citrate positive $\left(\mathrm{Cit}^{+}\right)$lactococci (i.e. Streptococcus diacetylactis and Lactococcus lactis ssp. lactis biovar diacetylactis), Leuconostoc mesenteroides ssp. cremoris and Leuconostoc lactis [9]. Non Starter Lactic Acid Bacteria (NSLAB) and molds may be also involved in citrate metabolism [10-11]. Lactic acid is also a natural constituent of milk, since it is the final product of lactic fermentation, carried out by lactic acid bacteria (LAB). The most representative LAB in mozzarella are Lactobacillus spp., Lactococcus spp. and Streptococcus thermophilus [12]. The 
lactic acid levels result very variable in these products, in relationship to raw material characteristics (endogenous microflora, total carbohydrates, etc.), production technologies and storage/packaging conditions.

The question is simple, how can we verify if a mozzarella cheese has been made without added food additives? Quantifiable amounts of citric acid and lactic acid will be often detected also in products without added food additives, and the food inspections, carried out on these types of matrix, could give a not-correctly formulated response ("not-compliant" not corresponding to a real food additives addition) [13].

This work is collocated in this contest. It may be considered as a contribution for a correct food additives determination in mozzarella cheese. 14 samples ( 7 with citric acid declared on the label and 7 without declared food additives) were analysed, by using a reliable analytical method by ion chromatography with conductivity detection, for the determination of citric acid. The results were compared in order to verify a statistically significant difference between two data populations.

Regarding lactic acid, 14 samples without this food additive declared on the label were analysed, by using a validated ion chromatography with conductivity detection method, in order to statistically analyse the obtained data and then to elaborate a "maximum admissible level" to suggest for lactic acid in mozzarella cheese without added food additives.

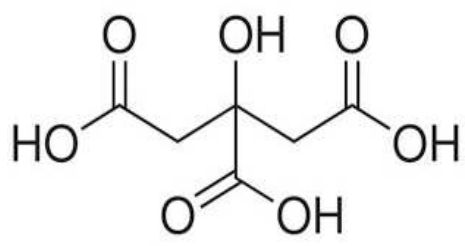

CITRIC ACID

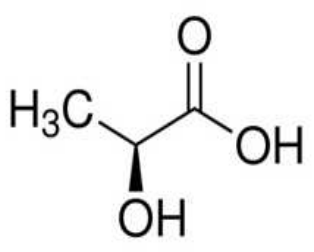

LACTIC ACID
Figure 1. Compounds analysed in this study

\section{Materials and Methods}

Lactic acid solution $(\geq 85 \%)$ and citric acid $(\geq 99.5 \%)$ were purchased from Sigma-Aldrich (Stenheim, Germany). Sodium hydroxide $(50 \% \mathrm{w} / \mathrm{w})$ and sodium carbonate $(99.5 \%)$ were supplied by J.T. Baker (Deventer, Netherlands). All solutions used for ion-exchange chromatography were prepared with ultrapure water (minimal resistance $18.2 \mathrm{M} \Omega-\mathrm{cm}$ ), supplied by Milli-Q RG unit from Millipore (Bedford, MA, USA). Sodium carbonate and sodium hydroxide solutions, used as eluents, were prepared by dilution in ultrapure water, degassing with nitrogen. The analytical determinations were carried out by using a Dionex system (Dionex Corporation, Sunnyvale, CA) composed of a GP50 quaternary gradient pump, a Rheodyne injection valve (model RH9125, Cotati, CA, USA) with a 25 $\mu \mathrm{L}$ injection loop, an electrochemical detector (model ED40) set to conductivity mode equipped with a temperature compensated conductivity cell and a Dionex anion self-regenerating suppressor (ASRS II, $4 \mathrm{~mm}$ ), used for the electrochemical suppression at an operative current of 50 $\mathrm{mA}$. The plastic reservoir bottles (DX500 2L bottles, Dionex) were closed and pressurized with pure nitrogen to $0.8 \mathrm{MPa}$. The system was interfaced via proprietary network chromatographic software $\left(\right.$ PeakNet $^{\circledR}$, Dionex Corporation, Sunnyvale, CA) to a personal computer for instrumentation control, data acquisition and processing.

\subsection{Citric Acid Determinations}

A 4-g portion of the sample, homogenised by a blade homogeniser, was placed in a $50 \mathrm{~mL}$ polypropylene tube and mixed with $40 \mathrm{~mL}$ of deionised water. The analyte extraction was obtained by vortexing (Digital vortex mixer, VWR Int., Milan, Italy) for 1 minute. The sample purification was carried out through a centrifugation (Jouan BR4i centrifuge, Thermo Fisher, Milan, Italy; 1500 x g, 10 minutes at room temperature) and a subsequent filtration of supernatant through Whatman No.40 filters (Whatman, Springfield Mill, UK). Finally, $1.5 \mathrm{~mL}$ of filtrate were filtered again by using Anotop $10 \mathrm{LC}$ filters $(0.2 \mu \mathrm{m}, 10 \mathrm{~mm}$, Whatman, Springfield Mill, UK) prior to chromatographic analysis. The chromatographic separations, related to citric acid determinations, were performed using an IonPac AS11-HC column $(250 \mathrm{~mm} \times 4 \mathrm{~mm}$ i.d., particle size: $13 \mu \mathrm{m}$, Dionex Corporation, Sunnyvale, CA), by following and modifying properly an Application Note proposed by Dionex Corporation for the determination of organic acids [14]. The gradient elution was set at a flow rate of $1.0 \mathrm{~mL} \mathrm{~min}^{-1}$. The mobile phase consisted of $38.25 \mathrm{mM} \mathrm{NaOH}$ (A) and $0.5 \mathrm{mM}$ $\mathrm{NaOH}$ (B). The solvent program started with a linear gradient from $0 \%$ to $10 \% \mathrm{~A}$ in 12 minutes, isocratic for 5 minutes and then up to $100 \% \mathrm{~A}$ in 1 minute. The mobile phase composition remained constant for a further 3 minutes and, finally, the system was re-equilibrated for 4 minutes at $100 \%$ A. The instrumental calibration was obtained by analyzing four citric acid standard solutions at concentrations equal to $6.25,12.5,25$ and $50 \mathrm{mg} \mathrm{L}^{-1}$. The determination coefficient $\left(\mathrm{r}^{2}\right)$ obtained was equal to 0.998 .

\subsection{Lactic Acid Determinations}

A 4-g portion of the sample, homogenised by a blade homogeniser, was placed in a $50 \mathrm{~mL}$ polypropylene tube and mixed with $40 \mathrm{~mL}$ of $8.5 \cdot 10^{-3} \mathrm{M} \mathrm{NaOH}$. This particular solution allows an optimal analytes extraction from matrix and an increment of method sensibility (by increasing organic acids dissociation). The analyte extraction was obtained by placing the tube in ultrasonic bath (Transsonic Digitals, Elma Instruments, Singen, Germany. Ultrasound power: $80 \%$; Heating: $40^{\circ} \mathrm{C}$ ) for 10 minutes and then vortexing for 1 minute. The sample purification was carried out through a centrifugation (1500 x g, 10 minutes at room temperature) and a consequent filtration of $\sim 5 \mathrm{~mL}$ of supernatant by using Minisart ${ }^{\circledR}$ GF syringe filters $(0.2 \mu \mathrm{m}$, Sartorius AG, Goettingen, Germany). A final removing of 
excess chlorides was obtained by using OnGuard II Ag chromatography filters (Dionex Corporation, Sunnyvale, CA), previously activated with $1 \mathrm{~mL}$ of deionised water. About $1 \mathrm{~mL}$ of filtrate was purified and then injected into HPIC system.

The chromatographic separations were obtained by using an anion exchange column IonPac AS9-HC $(250 \mathrm{~mm} \times 4 \mathrm{~mm}$ i.d., particle size: $9 \mu \mathrm{m}$, Dionex Corporation, Sunnyvale, CA) eluted in gradient mode at a flow rate of $1.0 \mathrm{~mL} \mathrm{~min}^{-1}$. The mobile phase consisted of $0.9 \mathrm{mM} \mathrm{Na}_{2} \mathrm{CO}_{3}(\mathrm{~A})$ and $28.5 \mathrm{mM}$ $\mathrm{Na}_{2} \mathrm{CO}_{3}$ (B). The multilinear gradient, at room temperature, consisted of a linear gradient from $0.9 \mathrm{mM}$ to $3.7 \mathrm{mM}$ in 5 minutes, from $3.7 \mathrm{mM}$ to $9.2 \mathrm{mM}$ in $1 \mathrm{~min}$, an isocratic step for 19 minutes, then a linear gradient from $9.2 \mathrm{mM}$ to 28.5 $\mathrm{mM}$ in 1 minute and 4 minutes at this eluent concentration. The system was finally re-equilibrated for $10 \mathrm{~min}$ at $0.9 \mathrm{mM}$ $\mathrm{Na}_{2} \mathrm{CO}_{3}$. This analytical procedure was submitted to a validation procedure, by following the most important European Directive and Guidelines [15-18]. The entire procedure of validation was fully described elsewhere [19]. Briefly, the analytical method was characterised by high specificity and ruggedness (ascertained for dairy products), suitable linearity $\left(\mathrm{r}^{2}=0.992\right)$, good precision (expressed as $\mathrm{CV} \%$, equal to $9.4 \%, \mathrm{n}=6$ ), optimal recovery percentage $(92.3 \%)$, low limits of determination (LOD) and quantification (LOQ), equal to 0.6 and $1.9 \mathrm{mg} \mathrm{kg}^{-1}$, respectively, and measurement uncertainty equal to $12.7 \%$.

\section{Results and Discussion}

\subsection{Citric Acid}

All data obtained by analyzing 14 mozzarella cheese samples ( 7 with citric acid declared on the label and 7 without declared food additives) are reported in table 1. As expected, a quantifiable amount of citric acid was detected in all analysed samples at concentrations levels higher than $0.101 \mathrm{~g} \mathrm{~kg}^{-1}$. A high data variability was verified both in samples with added citric acid (in the range $0.705-1.676 \mathrm{~g}$ $\mathrm{kg}^{-1}$ ) and in samples with no added food additives (in the range $0.101-0.608 \mathrm{~g} \mathrm{~kg}^{-1}$ ). However, as shown in Figure 2, the two categories of samples were characterised by not overlapped concentrations. Moreover, ANOVA one-way test confirmed a significant difference between two data populations. This is in agreement with those already reported in a recent study [8]. In particular, the samples with added citric acid showed concentrations higher than $0.705 \mathrm{~g} \mathrm{~kg}^{-1}$; while the samples with no added food additives showed concentrations lower than $0.608 \mathrm{~g} \mathrm{~kg}^{-1}$. As a result, a citric acid level equal to $0.650 \mathrm{~g} \mathrm{~kg}^{-1}$ was suggested, in this preliminary study, as "cut-off" value, useful to discriminate samples with added citric acid from those not added. In Figure 3, two chromatograms (a standard solution and a mozzarella sample) are shown.

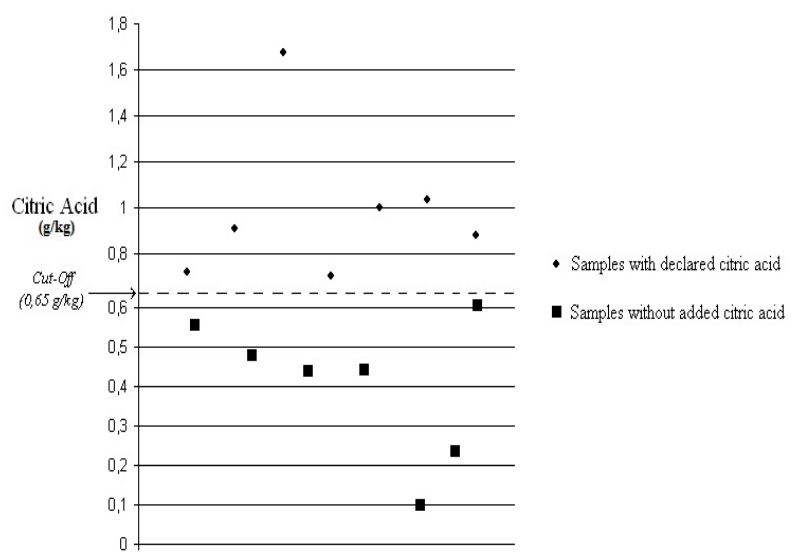

Figure 2. Distribution of citric acid concentrations detected in mozzarella samples
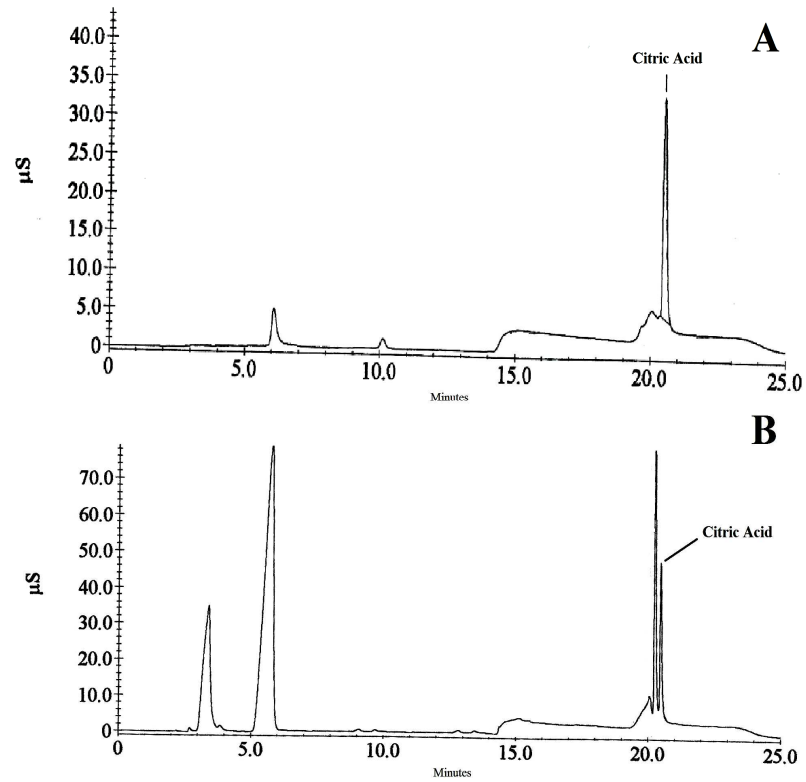

Figure 3. Chromatograms of a citric acid standard solution at a concentration of $25 \mathrm{mg} \mathrm{L}^{-1}$ (A) and a mozzarella sample with a quantified citric acid level equal to $0.558 \mathrm{~g} \mathrm{~kg}^{-1}$ (B)

\subsection{Lactic Acid}

All data obtained by analyzing 14 mozzarella cheese samples are reported in table 1. As expected, a quantifiable amount of lactic acid was detected in all analysed samples, at concentrations higher than $0.022 \mathrm{~g} \mathrm{~kg}^{-1}$. The concentration range obtained corresponded to $0.022-3.688 \mathrm{~g} \mathrm{~kg}^{-1}$, with a mean level equal to $1.406 \mathrm{~g} \mathrm{~kg}^{-1}$. In Figure 4, a graphical elaboration of these data is shown. Due to wide range of obtained concentrations, it was not possible to adopt a similar approach to those already proposed in another similar study [20], to estimate a maximum "natural" level for lactic acid in mozzarella samples. However, the levels registered in this study were all lower than $4.0 \mathrm{~g} \mathrm{~kg}^{-1}$; therefore, this concentration may be proposed, as a first step, as reference value. Below this level, the lactic acid concentrations may be attributed to LAB metabolism and not to food additives addition. In Figure 5, two chromatograms (a standard 
solution and a mozzarella sample) are shown.

Table 1. Results obtained by analyzing 14 mozzarella samples

\begin{tabular}{|c|c|c|c|c|}
\hline Food Additive & Number of samples analysed & $\begin{array}{l}\text { Lowest concentration } \\
\text { detected }\left(\mathrm{g} \mathrm{kg}^{-1}\right)\end{array}$ & $\begin{array}{l}\text { Highest concentration } \\
\text { detected }\left(\mathrm{g} \mathrm{kg}^{-1}\right)\end{array}$ & $\begin{array}{l}\text { Mean concentration detected } \\
\left(\mathrm{g} \mathrm{kg}^{-1}\right)\end{array}$ \\
\hline \multirow{2}{*}{ Citric Acid } & 7 (without declared food additives) & 0.101 & 0.608 & 0.409 \\
\hline & 7 (with declared citric acid) & 0.705 & 1.676 & 0.990 \\
\hline Lactic acid & 14 (without declared lactic acid) & 0.022 & 3.688 & 1.406 \\
\hline
\end{tabular}
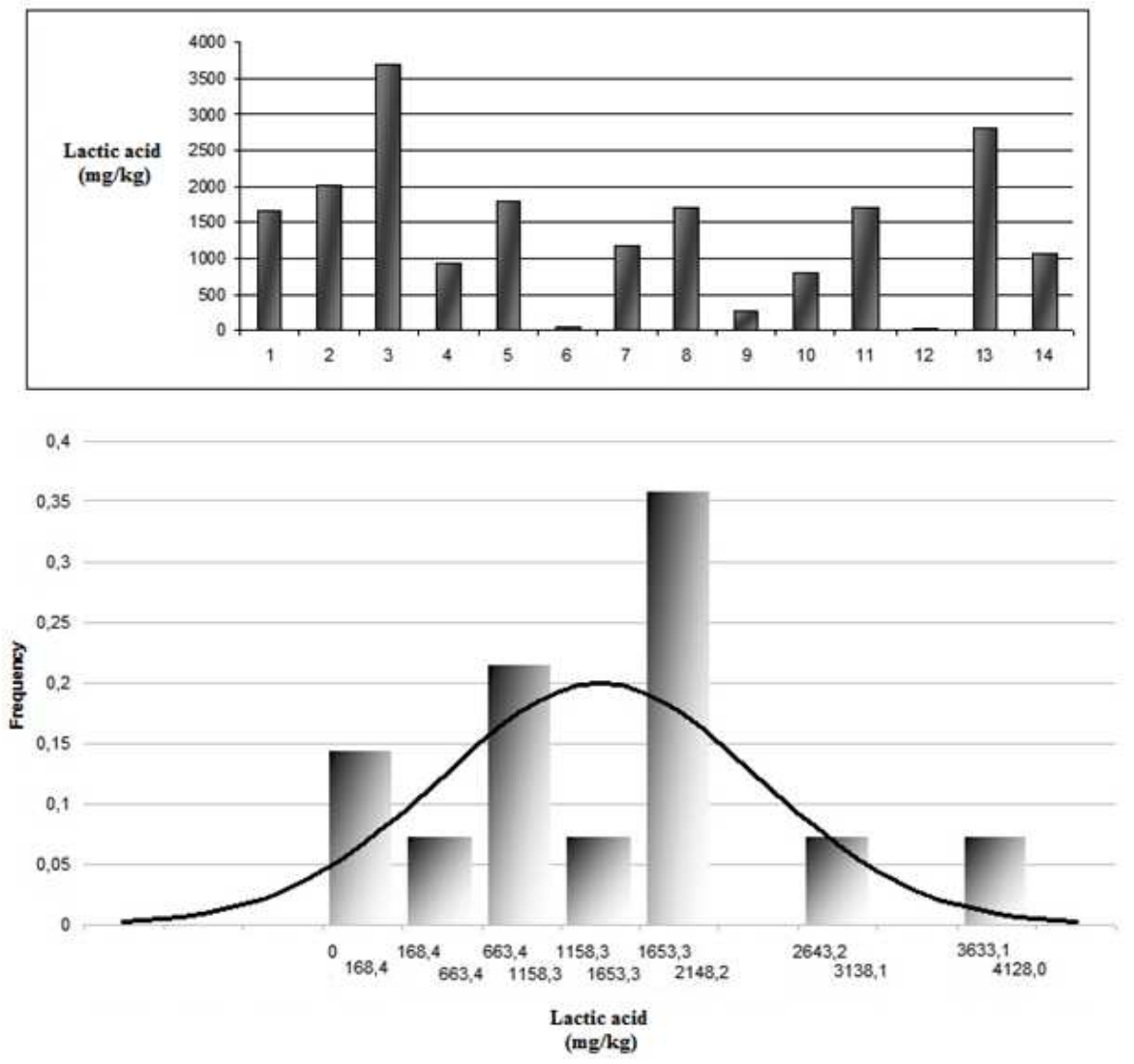

Figure 4. Distribution of lactic acid concentrations detected by analyzing 14 mozzarella samples

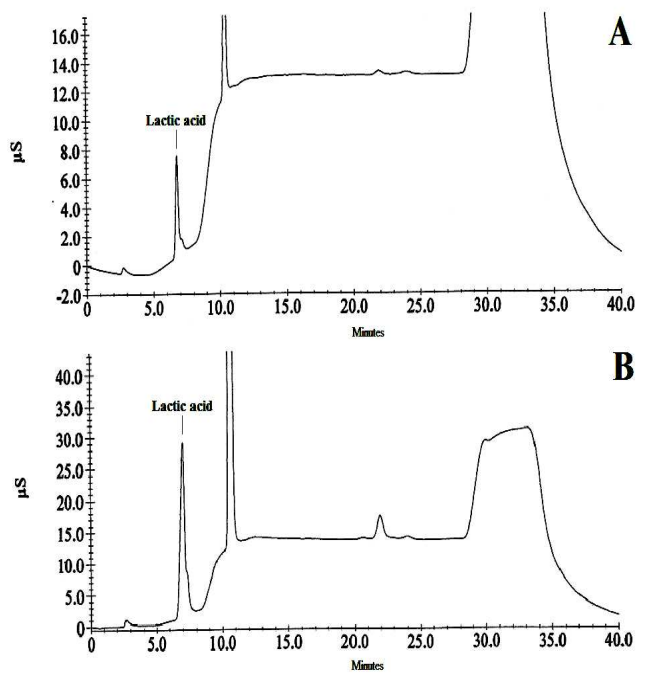

Figure 5. Chromatograms of a lactic acid standard solution at a concentration of $50.0 \mathrm{mg} \mathrm{L}^{-1}(A)$ and a mozzarella sample with a quantified lactic acid level equal to $2.014 \mathrm{~g} \mathrm{~kg}^{-1}(B)$

\section{Conclusion}

In this work, 14 mozzarella samples (7 with declared citric acid and 7 without declared food additives) were analysed, in order to quantify the levels of citric acid and lactic acid. Two reliable analytical methods, which employ ion chromatography with conductivity detection, were used to carry out the quantification of these two food additives. The analytical methods, fully described in this work, allowed a precise and specific quantification of citric acid and lactic acid in mozzarella samples. Citric acid was quantified both in samples with added citric acid and in samples without added food additives. However, the two categories of samples were characterised by not overlapped concentrations. Consequently, a citric acid level equal to $0.65 \mathrm{~g} \mathrm{~kg}^{-1}$ was suggested, in this preliminary study, as "cut-off" value, useful to discriminate samples with added citric acid from those not added. Regarding lactic acid, this compound was quantified in all analysed samples and, as a first step, a "natural" maximum level of lactic acid equal to $4.0 \mathrm{~g} \mathrm{~kg}^{-1}$ was 
suggested as reference value, useful to discriminate samples with added lactic acid from those not added.

\section{Acknowledgements}

The Istituto Zooprofilattico Sperimentale della Puglia e della Basilicata (Foggia, Italy) is thanked for providing financial support.

\section{References}

[1] Codex Alimentarius. Codex Standard for Mozzarella - CODEX STAN 262-2006, 2006.

[2] European Commission. Commission Regulation (EU) No. 1129/2011 of 11 November 2011 amending Annex II to Regulation (EC) No 1333/2008 of the European Parliament and of the Council by establishing a Union list of food additives. Journal of the European Union, L295, 1-177, 2011.

[3] Bamidele O., and Adejumo I.O. Variability of citric acid in cow milk composition. International Journal of AgriScience, 2(3), 192-199, 2012.

[4] Alais C. Scienza del latte $\left(3^{\text {rd }}\right.$ ed). Le sostanze minerali. Gli acidi organici. Tecniche Nuove, Milano, Italy; pp. 195-196, 2000 .

[5] Rosenthal, I. Milk and dairy products: properties and processing. In: Balaban Publishers VCH Ed. Chemistry of milk components. B.P. VCH, New York, NY, p.36, 1991.

[6] Gaucheron, F. The minerals of milk. Reprod Nutr Dev, 45, 473-483, 2005.

[7] Garnsworthy P.C., Masson L.L., Lock A.L., Mottram T.T. Variation of milk citrate with stage of lactation of de novo fatty acid synthesis in dairy cows. J Dairy Sci, 89, 1604-1612, 2006.

[8] Iammarino M., Di Taranto A., Palermo C., Muscarella M. Assessment of Natural Levels of Substances with Preservative Effects in Dairy Products. In: Castelli H., du Vale L. Eds., Handbook on Cheese: Production, Chemistry and Sensory Properties. Nova Publisher, NY, USA, pp. 559-572, 2013.

[9] Mc Sweeney P.L.H. Biochemistry of cheese ripening. International Journal of Dairy Technology, 57(2-3), 127-144, 2004.
[10] Palles T., Beresford T., Condon S., Cogan T.M. Citrate metabolism in Lactobacillus casei and Lactobacillus plantarum. Journal of Applied Microbiology, 85, 147-154, 1998.

[11] el-Samragy Y.A., Khorshid M.A., Foda M.I., Shehata A.E. Effect of fermentation conditions on the production of citric acid from cheese whey by Aspergillus niger. Int $\mathrm{J}$ Food Microbiol, 29(2-3):411-6, 1996.

[12] Losito F., Arienzo A., Bottini G., Priolisi F.R., Mari A., Antonini G. Microbiological safety and quality of Mozzarella cheese assessed by the microbiological survey method. Journal of Dairy Science 97:46-55, 2014.

[13] Iammarino M., Di Taranto A. Foodstuffs without Added Food Additives: The Needing of a Normative Update. Journal of Nutrition and Nutritional Epidemiology, 1(1):1-5, 2014.

[14] Dionex Corporation. Product manual for IonPac ${ }^{\circledR}$ AS11-HC IonPac ${ }^{\circledR}$ AG11-HC. Document No. 031333-07. Sunnyvale, CA, USA, 2008.

[15] European Commission. Decision (EC) No. 657/2002. 12 August 2002. Official Journal of the European Union. L221: $8-36,2002$.

[16] European Commission. Regulation (EC) No. 882/2004. 29 April 2004. Official Journal of the European Union. L165: 1-141, 2004.

[17] Miller E.J.C., Miller J.N. Statistics for Analytical Chemistry. $3^{\text {rd }}$ ed. New York (USA): Ellis Horwood PTR Prentice Hall, p.115, 1993.

[18] Youden W.J., Steiner E.H. Statistical Manual of the AOAC. Washington DC (USA): Association of the Official Analytical Chemists, p. 35, 1975.

[19] Iammarino M., Di Taranto A. Development and validation of an ion chromatography method for the simultaneous determination of seven food additives in cheeses. Journal of Analytical Sciences, Methods and Instrumentation, 3, 30-37, 2013.

[20] Iammarino M., Di Taranto A., La Salandra G. Correlation between nitrate levels and microbiological safety in shellfish (missels and clams): a preliminary study. In: Hay RM Ed., Shellfish - Human consumption, health implications and conservation concerns. Nova Publisher, NY, USA, pp. 195-209, 2014. 